\title{
Pre-weaning plane of nutrition and Mannheimia haemolytica dose influence inflammatory responses to a bovine herpesvirus-1 and Mannheimia haemolytica challenge in post-weaning Holstein calves
}

\author{
K. P. Sharon, ${ }^{1,2}$ Y. Liang, ${ }^{1}$ N. C. Burdick Sanchez, ${ }^{2}$ J. A. Carroll, ${ }^{2}$ P. R. Broadway, ${ }^{2}$ E. M. Davis, ${ }^{1}$ \\ and M. A. Ballou ${ }^{1 *}$ \\ ${ }^{1}$ Texas Tech University, Department of Animal and Food Sciences, Lubbock 79409 \\ ${ }^{2}$ USDA-Agricultural Research Service, Livestock Issues Research Unit, Lubbock, TX 79403
}

\section{ABSTRACT}

The objectives of this study were to determine whether plane of nutrition (PON) of milk replacer previously provided to calves, and dosage level of Mannheimia haemolytica (MH), influenced inflammatory responses to a combined viral-bacterial respiratory challenge. Holstein calves ( $1 \mathrm{~d}$ of age; $\mathrm{n}=30$ ) were assigned to treatments in a $2 \times 3$ factorial with preweaning $\mathrm{PON}$ and $\mathrm{MH}$ dose as main effects $(\mathrm{n}=5$ per treatment). Calves were fed either a low (LPN; $\mathrm{n}=$ $15)$ or a high PON (HPN; $\mathrm{n}=15)$ from birth through weaning. Calves fed LPN were fed $436 \mathrm{~g}$ of dry matter (DM) per day of milk replacer until weaning, and HPN calves were fed $797 \mathrm{~g}$ of DM per day of milk replacer from $\mathrm{d} 1$ to 10 and 1,080 $\mathrm{g}$ of DM per day from $\mathrm{d} 11$ until weaning. Calf starter and water were offered ad libitum. Calves were step-down weaned beginning at $d$ 54 and moved into an enclosed barn at d 70. Indwelling rectal temperature (RT) recording devices and jugular catheters were inserted at $\mathrm{d} 80$. Calves were challenged with $1.5 \times 10^{8}$ plaque-forming units (pfu) per $\mathrm{mL}$ of bovine herpesvirus-1 (BHV-1) in each nostril at $\mathrm{d} 81$ and with either $10^{6}, 10^{7}$, or $10^{8}$ cfu of $\mathrm{MH}$ at d 84 . Blood samples were collected at varying intervals relative to BHV-1 and MH challenges. Four LPN calves either died or were euthanized soon after the 144-h observation period, whereas all HPN calves survived the entire observation period. As dosage of $\mathrm{MH}$ administered increased, acute and systemic inflammatory responses increased. Higher doses of $\mathrm{MH}$ resulted in increased leukocyte, neutrophil, and haptoglobin concentrations in infected calves. Data from the current study suggest that the highest dose, $10^{8} \mathrm{cfu}$, triggered weaned calves' acute disease response, whereas the lower doses, $10^{6}$

Received November 14, 2018.

Accepted June 4, 2019.

*Corresponding author: michael.ballou@ttu.edu and $10^{7} \mathrm{cfu}$, caused more moderate inflammation and disease. The effects of PON on inflammation responses to the disease challenge indicated that calves previously fed the LPN diet had more severe pathophysiological responses. Calves fed LPN showed higher peripheral neutrophil and leukocyte counts and serum haptoglobin concentrations following the BHV-1 challenge. Additionally, following the MH challenge, LPN calves had higher peripheral neutrophil counts, neutrophil-tolymphocyte ratios, and serum tumor necrosis factor- $\alpha$ concentrations. These data demonstrate that higher doses of $\mathrm{MH}$ increase the acute inflammatory response and prolong inflammation, and that calves previously fed LPN responded more severely to the combined viral-bacterial respiratory challenge.

Key words: calves, health, nutrition, respiratory disease

\section{INTRODUCTION}

A common practice in the dairy industry is to restrict the quantity of milk solids fed to dairy calves, to accelerate calf-starter consumption and lower the age of weaning. Unfortunately, many dairy producers have adopted this management practice without understanding the long-term effects of restricting milk solids in early life. In fact, feeding greater quantities of milk solids, or higher planes of nutrition (PON), improved lactation performance later in life (Davis Rincker et al., 2011; Soberon et al., 2012). Less is known regarding how the quantity of milk solids fed to calves during the pre-weaning period influences the health of calves later in life. A study conducted by Ballou (2012) reported reduced neutrophil oxidative burst and whole-blood killing of an enteropathogenic Escherichia coli a month after weaning among Jersey calves that were previously fed a restricted quantity of milk replacer (MR), or low PON. In a follow-up study, Ballou et al. (2015) reported that Jersey calves previously fed a restricted quantity of MR had delayed activation of leukocytes 
following a mild oral challenge with Salmonella enterica serotype Typhimurium a month after weaning. In that same study, the calves that were fed the restricted diet during the pre-weaning period had greater systemic inflammation, as evidenced by elevated plasma haptoglobin concentrations. These data suggest that calves fed a low PON may have impaired leukocyte responses and subsequent reduced disease resistance that persists past the pre-weaning period.

Bovine respiratory disease complex (BRDC) is the leading cause of morbidity and mortality among growing cattle (NAHMS, 2007, 2011). Infections due to BRDC are often characterized by a primary viral infection followed by a secondary bacterial infection; therefore, a viral-bacterial challenge may be the most appropriate model to emulate a spontaneous BRDC infection. The dosage of the infectious pathogen in an experimental challenge model may influence the outcome. If the pathogen dose is too low, all animals may not develop clinical disease; therefore, a low-level dose of the pathogen may be an appropriate model to evaluate disease resistance. In contrast, a high dose of the pathogen may overwhelm the immune system, and all animals will rapidly develop clinical disease, rendering this model a better reflection of the disease response. Both of these models answer important questions about the overall health of animals. Therefore, the objectives of this study were (1) to determine whether previous PON of MR influences the inflammatory responses to a combined viral-bacterial respiratory challenge, and (2) to evaluate whether the response was influenced by the dose of bacteria used in the challenge. The hypotheses of this study were that (1) calves fed a higher PON of MR during pre-weaning would have a less-severe inflammation response to a viral-bacterial respiratory disease challenge and (2) a higher bacterial dose will induce more severe inflammation and disease.

\section{MATERIALS AND METHODS}

\section{Experimental Design}

All experimental procedures were in compliance with the Guide for the Care and Use of Agricultural Animals in Research and Teaching (FASS, 2010) and approved by the Institutional Animal Care and Use Committees of Texas Tech University and the USDA-ARS Livestock Issues Research Unit. The study was conducted from July to September 2014. Thirty-six Holstein bull calves with (mean \pm SD) weight of 39.3 and $39.5 \pm 5.92 \mathrm{~kg}$ for LPN and HPN, respectively, were acquired from a local calf ranch within $24 \mathrm{~h}$ of birth and transported $105 \mathrm{~km}$ to the Texas Tech University Hilmar Cheese Calf Research Facility in New Deal, Texas, a biosecurity level
1 facility. Calves were housed and managed similarly to industry-standard commercial operations. At enrollment, peripheral blood was collected from each calf into a tube with no additives, to be analyzed by a handheld refractometer to assess passive immunity status. Calves with $<5.2 \mathrm{~g} / \mathrm{dL}$ of total serum protein were deemed to have failure of passive transfer of immunity. Calves in the high plane of nutrition (HPN) treatment and the low plane of nutrition (LPN) treatment did not differ, with $72 \%$ and $76 \%$ having failure of passive transfer of immunity, respectively. Calves were $3 \mathrm{~d}$ of age when enrolled into the study and randomly assigned to either a low or a high plane of MR nutrition (Table 1). Body weight at enrollment did not differ between the 2 treatments. Calves fed LPN $(\mathrm{n}=18)$ were fed $436 \mathrm{~g}$ of DM per d of a $20 \%$ CP, $20 \%$ lipid MR at $10.4 \%$ solids DM (Herd Maker, Land O'Lakes Animal Milk Products Co., Shoreview, MN). Calves fed HPN ( $\mathrm{n}=18$ ) were fed $797 \mathrm{~g}$ DM per d from d 1 to 10 and 1,180 g DM per $\mathrm{d}$ from d 11 until weaning of a $28 \%$ CP, $20 \%$ lipid MR at 14.9 and $15.5 \%$ solids DM, respectively (Cow's Match, Land O'Lakes Animal Milk Products Co.). Calves were fed MR from bottles twice daily at 0730 and $1630 \mathrm{~h}$. All calves were offered ad libitum access to water and a texturized calf starter (Purina Animal Nutrition LLC, Shoreview, MN) following the first $3 \mathrm{~d}$ (Table 1). The HPN was not an ad libitum access to milk solids, and the LPN was formulated to represent a common industry method of feeding approximately $454 \mathrm{~g}$ of milk solids per day with ad libitum access to calf starter. Calves were vaccinated with a 5 -way (IBR, BVDV I and II, BRSV, PI3; Triangle 5, Boehringer Ingelheim, St. Joseph, MO) respiratory virus vaccine at $28 \mathrm{~d}$ and a booster at $42 \mathrm{~d}$. Neutralizing antibody titers from maternal sources were not determined before vaccination; however, as reported previously, approximately two-thirds of the calves in the study had failure of passive transfer of maternal immunoglobulin. Calves were step-down weaned beginning at $\mathrm{d} 54$, and 30 of the calves $(\mathrm{n}=15$ per PON treatment) were transported $5 \mathrm{~km}$ from the Texas Tech University Hilmar Cheese Calf Research facility to the USDA-ARS Livestock Issues Research Unit's Research Complex at d 70. Of the initial 36 calves, 4 (2 LPN and $2 \mathrm{HPN}$ ) died before weaning. Of the remaining 32,1 calf had to be removed from the HPN treatment due to constant bloating; therefore an LPN calf was randomly selected for removal from the 31 remaining calves so that each PON treatment would contain the same number of calves $(\mathrm{n}=15)$. Calves were randomly assigned to treatments in a $2 \times 3$ factorial, with pre-weaning PON level and Mannheimia haemolytica (MH) dose as the main effects ( $\mathrm{n}=5$ per treatment combination). The sample size was based on HPN and LPN neutrophil-to- 
Table 1. Formulated nutrient contents of commercial milk replacers, fed at low and high planes of nutrition (LPN and HPN, respectively) and calf starter

\begin{tabular}{lccc}
\hline & \multicolumn{2}{c}{ Milk replacer $^{1}$} & Starter $^{2}$ \\
\cline { 2 - 4 } Nutrient & LPN & HPN & \\
\hline DM, \% & 97 & 98 & 95 \\
CP, $\%$ & 20 & 28 & 20 \\
Ether extract, \% & 20 & 20 & 2.5 \\
ADF (maximum), $\%$ & 0.15 & 0.15 & 3.00 \\
ME, ${ }^{3}$ Mcal/kg & 4.65 & 4.75 & 0.90 \\
Calcium, \% & 0.75 & 0.75 & 0.45 \\
Phosphorus, \% & 0.7 & 0.7 & 2,955 \\
Vitamin A (minimum), IU/kg & 44,000 & 44,000 & - \\
Vitamin $\mathrm{D}_{3}$ (minimum), IU/kg & 11,000 & 11,000 & - \\
Vitamin E (minimum), IU/kg & 220 & 330 & - \\
\hline
\end{tabular}

${ }^{1}$ Two commercial milk replacers were fed (LPN = Herd Maker; HPN = Cow's Match; Land O'Lakes Animal Milk Products Co., Shoreview, MN). Both milk replacers were formulated with similar macro- and microingredients and included dried whey, dried whey protein concentrate, dried whey product, dried skim milk, dried milk protein, animal fat, lecithin, polysorbate 80, dicalcium phosphate, calcium carbonate, brewers dried yeast, vitamin $A$ acetate, $d-\alpha$ tocopherol acetate, vitamin $D_{3}$, thiamine monohydrate, riboflavin, niacin supplement, folic acid, vitamin $\mathrm{B}_{12}$ supplement, choline chloride, zinc methionine complex, manganese methionine complex, copper lysine complex, iron amino acid complex, ethylenediamine dihydroiodide, selenium yeast, and natural and artificial flavor.

${ }^{2}$ A single commercial calf starter was fed across groups (Ampli-Calf 20, Purina Animal Nutrition LLC, Shoreview, MN). Ingredients included grain products, plant protein products, processed grain by-products, molasses products, roughage products, calcium carbonate, salt, soybean oil, propionic acid, vitamin E supplement, sodium selenite, ferrous sulfate, vitamin $\mathrm{D}_{3}$ supplement, yeast extract, copper sulfate, copper amino acid complex, manganese sulfate, zinc amino acid complex, ethylendediamine dihydroiodide, cobalt glucoheptonate, fructooligosaccharide, mineral oil, natural and artificial flavors, selenium yeast, chromium propionate, and propylene glycol.

${ }^{3}$ Calculated based on NRC (2001).

lymphocyte ratio means after the respiratory challenge of 1.2 and 1.5 , respectively, with a standard deviation of 0.18. Acceptable type I and II errors were 5 and $20 \%$, respectively. Calves were housed in individual stalls $(2.13 \mathrm{~m}$ long $\times 0.76 \mathrm{~m}$ wide $)$ and offered ad libitum access to water and to the same commercially available texturized calf starter that had been fed during the pre-weaning period, for the remainder of the study. The stall flooring was a 2.5 -cm-thick rubber mat, and calves were able to turn around in their stalls.

Calves were weighed individually on arrival at the USDA facility at d 70 and on d 90, the last day of the study. At d 80, calves were fitted with indwelling jugular vein cannulas and indwelling rectal temperature (RT) recording devices (Reuter et al., 2010) that measured RT at 5-min intervals for the remainder of the study. For jugular cannulation, a small, 2- to $3-\mathrm{cm}$ incision was made in the skin to more easily access the jugular vein. Temporary indwelling jugular cannulas, consisting of approximately $30.5 \mathrm{~cm}$ of sterile Tygon tubing (AAQ04133, US Plastics, Lima, OH; 1.27-mm internal diameter and $2.29-\mathrm{mm}$ outer diameter), were inserted into the jugular vein using a 14-gauge by 5.08$\mathrm{cm}$ thin-walled stainless steel biomedical needle (outer diameter $=3 \mathrm{~mm}$ ). The catheter was maintained in place using tag cement and 2.08-cm-wide porous surgi- cal tape around the incision site, and then the entire neck region of each calf was wrapped with vet wrap (VetRap, 3M Animal Care Products, St. Paul, MN) to ensure stability of the catheterization site. Remaining tubing not inserted into the vein served as the extension portion of the cannula for collection of blood samples. During these procedures, calves were restrained in a working chute for approximately 10 to $15 \mathrm{~min}$. The extension tubing of the cannula was extended above the stall, to allow researchers to collect blood throughout the study without disturbing calves, whether the calves were standing or lying down. The blood tubing was maintained with administration of $5 \mathrm{~mL}$ of saline into each tube between every blood draw and $5 \mathrm{~mL}$ of heparinized saline once per day.

\section{Respiratory Challenge}

Thirty individual vials with $1.5 \times 10^{8}$ pfu of bovine herpesvirus-1 (BHV-1) were reconstituted with $2 \mathrm{~mL}$ of sterile $1 \times$ PBS. The BHV-1 used in this study was the Cooper strain obtained from Texas Vet Lab Inc. (San Angelo, TX). Two syringes per calf, each containing $1 \mathrm{~mL}$ of reconstituted virus, were fitted with a mucosal atomization device. Each calf was inoculated on $\mathrm{d} 81$ at $1000 \mathrm{~h}$ with $1 \mathrm{~mL}$ of BHV-1 per nostril. 
On d 83, an individual colony of MH was aseptically placed from a tryptic soy agar plate into $25 \mathrm{~mL}$ of tryptic soy broth and incubated at $37^{\circ} \mathrm{C}$, shaking at $200 \mathrm{rpm}$ for $15 \mathrm{~h}$. This MH strain is Type A1 serotype, acquired from Texas Vet Lab Inc. After $15 \mathrm{~h}, 250 \mu \mathrm{L}$ of the overnight culture was sub-cultured into a new 25-mL tryptic soy broth. This culture was incubated at $37^{\circ} \mathrm{C}$, shaking at $200 \mathrm{rpm}$, until the culture reached an optical density of 0.8 at $400 \mathrm{~nm}$, which was previously determined to be approximately a concentration of 1 $\times 10^{8} \mathrm{cfu} / \mathrm{mL}$. Working concentrations of $2 \times 10^{4}, 10^{5}$, and $10^{6} \mathrm{cfu} / \mathrm{mL}$ were made in sterile $1 \times \mathrm{PBS}(\mathrm{pH}=$ 7.2). On d 84 at $1000 \mathrm{~h}$ (i.e., within $2 \mathrm{~h}$ of creating the working bacterial concentrations), calves were administered $50 \mathrm{~mL}$ of a total estimated dose of $2 \times 10^{6}, 10^{7}$, or $10^{8} \mathrm{cfu}$ of $\mathrm{MH}$ intratracheally. Estimates of the actual challenge doses were determined by spread plating 1:10 serial dilutions of the inoculum on tryptic soy agar plates immediately after performing the challenge. The actual challenge doses were $1.47 \times 10^{6}, 10^{7}$, and $10^{8} \mathrm{cfu}$. The observation period lasted until $144 \mathrm{~h}$ after the $\mathrm{MH}$ challenge, when all calves were treated with florfenicol and flunixin meglumine (Resflor Gold, Merck Animal Health, Roseland, NJ) per manufacturer's recommendations.

\section{Sample Collection}

Blood samples were collected from catheters using 3-mL evacuated tubes containing $\mathrm{K}_{2}$ EDTA (Vacutainer, Becton Dickinson, Rutherford, NJ) and 10-mL monovette tubes with no additive (S-Monovette, Sarstedt Inc., Newton, NC). Blood and saline were initially drawn up from the tubing; the first $5 \mathrm{~mL}$ of fluid was evacuated, and the next $5 \mathrm{~mL}$ of blood was collected. The $\mathrm{K}_{2}$ EDTA blood tube was used for hematology analysis, and serum was obtained from the no-additive tube after centrifugation at $1,500 \times g$ for 20 min at $4^{\circ} \mathrm{C}$. Serum was aliquoted and stored at $-80^{\circ} \mathrm{C}$ until subsequent analysis. Blood samples were collected immediately before the BHV-1 challenge $(-72 \mathrm{~h}$ relative to $\mathrm{MH}$ challenge), followed by collections every 6 $\mathrm{h}$ until $-6 \mathrm{~h}$ relative to the $\mathrm{MH}$ challenge. Beginning at $-2 \mathrm{~h}$ and continuing until $8 \mathrm{~h}$ relative to the $\mathrm{MH}$ challenge, serum samples were collected every $0.5 \mathrm{~h}$ and $\mathrm{K}_{2}$ EDTA tubes were collected every $1 \mathrm{~h}$. Both serum and $\mathrm{K}_{2}$ EDTA tubes were then collected at 12, 24, 36, 48,96 , and $144 \mathrm{~h}$ after the $\mathrm{MH}$ challenge.

\section{Nasal Lesion Score and Sickness Score}

A single trained observer assessed and recorded each calf's nasal lesion score each morning from -72 to 144 $\mathrm{h}$ relative to the $\mathrm{MH}$ challenge. Infectious bovine rhi- notracheitis (IBR) is an acute contagious respiratory disease caused by BVH-1 that can cause nasal lesions. Calves were scored using a new scale of 0 to 4 : $0=$ absence of definitive IBR lesions; $1=$ presence of lesions characteristic of IBR, affecting $10 \%$ or less of the visible nasal mucus membrane; $2=$ presence of lesions characteristic of IBR, affecting 11 to $25 \%$ of the visible nasal mucus membrane; $3=$ presence of lesions characteristic of IBR, affecting 26 to $50 \%$ of the visible nasal mucus membrane; $4=$ presence of lesions characteristic of IBR, affecting more than $50 \%$ of the visible nasal mucus membrane.

A single trained observer assessed and recorded a sickness score at each blood sampling time from -72 to $144 \mathrm{~h}$ relative to the $\mathrm{MH}$ challenge. Calves were scored using a new sickness score system of 0 to 4: 0 = alert, ears up; 1 = depressed, head distended, ears droopy; $2=$ head extended; 3 = lateral recumbency; 4 $=$ dead. The trained observers did not know the treatment assignments of each calf, but HPN calves visibly appeared to weigh more than the LPN calves did, so complete PON treatment blindness was not possible. However, both scoring systems used a standardized chart, to make the scoring less subjective.

\section{Sample Analysis}

All whole-blood samples were analyzed within $1 \mathrm{~h}$ of collection for complete blood count (CBC) using a ProCyte Dx Hematology Analyzer with bovinespecific algorithms to differentiate among lymphocytes, neutrophils, and monocytes (IDEXX Laboratories, Westbrook, ME). Serum antibody titers specific for BHV-1 were measured via virus neutralization by the Texas A\&M Veterinary Medical Diagnostic Laboratory (Amarillo, TX). Serum haptoglobin was quantified as described by Makimura and Suzuki (1982). A pooled serum sample was used to calculate the inter-assay coefficient of variation of $3.8 \%$ for the haptoglobin assay. All colorimetric data were measured on a SpectraMax 340PC (Molecular Devices, Sunnyvale, CA). Serum cytokine concentrations (TNF- $\alpha$ and IL-6) were determined by a custom bovine 3-plex sandwich-based chemiluminescence ELISA kit (Searchlight-Aushon BioSystems Inc., Billerica, MA). The minimum detectable concentrations were 0.5 and $3.3 \mathrm{pg} / \mathrm{mL}$ for $\mathrm{TNF}-\alpha$ and IL-6, respectively. All intra-assay coefficients of variation were $<9 \%$, and all inter-assay coefficients of variation were $<12 \%$ for all assays.

\section{Statistical Analysis}

Before analysis, RT data were averaged into 1-h intervals. Further, daily minimum, maximum, and range 
RT were calculated before analyses. Daily RT range was calculated by subtracting the minimum RT from the maximum RT for each day. Antibody titer data were logarithmically base- 2 transformed before analyses. Over time, the peaks of cytokine concentrations were variable among calves within any group. The means of treatment groups at each time point were not a good estimate of the central tendency for each group. Therefore, a more appropriate variable to consider was area under the curve (AUC) concentrations over time for each animal (Pruessner et al., 2003). Cytokine data were logarithmically base-10 transformed.

All repeated, continuous data were analyzed by restricted-maximum likelihood ANOVA using the Mixed procedure of SAS (version 9.4; SAS Institute Inc., Cary, $\mathrm{NC})$. All variables before the $\mathrm{MH}$ challenge $(0 \mathrm{~h})$ were analyzed utilizing a linear mixed model, with the fixed effects of PON, time, and their interactions. All continuous data following the $\mathrm{MH}$ challenge used a linear mixed model with the fixed effects of PON, MH dose, time, and their interactions. The subject of the repeated statement was calf nested within treatment. The mean model was run with all available covariance structures for the within-subject measurement. The appropriate covariance and variance structures were chosen for each analysis based on the Schwarz Bayesian information criterion. Mean comparisons at each time point were performed using a sliced-effect multiple comparison with a Duncan adjustment. Pairwise comparisons were made at each time point when the sliced-effect was significant, using the pairwise difference (PDIFF) statement. Normality of the residuals was confirmed by evaluating the Shapiro-Wilk statistic and normal probability plots using the Univariate procedure of SAS. Statistical significance was declared at $P \leq 0.05$, and a tendency was considered if $0.10 \leq P>0.05$. Data are presented as least squares means \pm the standard error of the mean.

\section{RESULTS}

Body weights at $70 \mathrm{~d}$ differed between LPN and HPN by design of the experiment $(63.1 \pm 2.05$ versus 81.0 $\pm 2.87 \mathrm{~kg} ; P \leq 0.001)$. Compensating for the reduced quantity of MR offered, the LPN calves consumed more calf starter during the pre-weaning period $(16.3 \pm 3.71$ $\mathrm{kg}$ versus $3.6 \pm 0.65 \mathrm{~kg} ; P \leq 0.001)$. Shortly after the conclusion of the study, 4 LPN calves died (1, 2, and 1 from the $10^{6}, 10^{7}$, and $10^{8} \mathrm{MH}$ doses, respectively), whereas none of the HPN calves died. Two calves died within $2 \mathrm{~d}$ of the completion of the study, and 2 more were euthanized $4 \mathrm{~d}$ after the completion of the study due to persistent anorexia and unresponsiveness to antimicrobial and non-steroidal anti-inflammatory drug treatments. Gross necropsies on all 4 calves revealed bilateral consolidated pneumonia involving more than $50 \%$ of the pulmonary tissue.

We found no significant $(P \geq 0.475) \mathrm{PON} \times \mathrm{MH}$ dose $\times$ time interactions for any variables reported, except for RT following the $\mathrm{MH}$ challenge. All data are reported as time relative to $\mathrm{MH}$ challenge; the $\mathrm{BHV}-1$ challenge took place $-72 \mathrm{~h}$ before the $\mathrm{MH}$ challenge. Nasal lesions were visible $1 \mathrm{~d}$ after the BHV-1 challenge. Peak nasal lesion scores occurred $1 \mathrm{~d}$ following the $\mathrm{MH}$ challenge and persisted throughout the observation period. Neither PON nor $\mathrm{MH}$ dose showed an effect on nasal lesion scores $(P \geq 0.483$; Table 2). All calves had a sickness score of 0 following the BHV-1 challenge (data not shown); however, the $\mathrm{MH}$ challenge caused clinical signs of sickness in many of the calves. We discovered a PON $\times \mathrm{MH}$ dose effect (Figure 1) in sickness scores following the $\mathrm{MH}$ challenge.

During the $\mathrm{BHV}-1$ challenge ( -72 to $0 \mathrm{~h}$ ), there was a PON $\times$ time interaction $(P<0.001)$ in RT (Figure 2a). The LPN calves initially had lower RT than the HPN calves did, but these increased in LPN calves to a greater degree compared with the RT of the HPN calves before the MH challenge. Further, LPN calves tended $(P=0.071)$ to have a wider daily $\mathrm{RT}$ range compared with HPN calves during the BHV-1 challenge (0.69 vs. $\left.0.58 \pm 0.042^{\circ} \mathrm{C}\right)$. Following the $\mathrm{MH}$ challenge, we found a $\mathrm{PON} \times \mathrm{MH}$ dose $\times$ time interaction $(P<0.001)$ on RT (Figure 2b-2d). Further, the LPN calves tended $(P$ $=0.087)$ to have a wider daily $\mathrm{RT}$ range compared with HPN calves following the MH challenge (1.00 vs. 0.84 $\left.\pm 0.062^{\circ} \mathrm{C}\right)$.

Proinflammatory cytokine concentrations are reported in Table 2. During the BHV-1 challenge, neither TNF- $\alpha$ AUC nor IL-6 AUC concentrations were different $(P \geq 0.472)$ between PON. After the MH challenge, LPN calves had higher $(P=0.029)$ TNF- $\alpha$ AUC concentrations, but IL-6 AUC concentrations were not different $(P \geq 0.414)$. An $\mathrm{MH}$ dose effect $(P \leq 0.025)$ was found for both TNF- $\alpha$ and IL-6 AUC concentrations. The $10^{8} \mathrm{cfu}$ treatment had greater serum TNF- $\alpha$ and IL- 6 than either the $10^{6}$ or the $10^{7}$ cfu treatments. Serum TNF- $\alpha$ AUC concentrations following the MH challenge were 2.04, 1.86, and $2.91 \pm 0.255$, and IL-6 AUC concentrations were 5.08, 5.27, and $6.74 \pm 0.415$ for the $10^{6}, 10^{7}$, and $10^{8}$ cfu treatments, respectively.

Selected hematology data during both the BHV-1 and the $\mathrm{MH}$ challenges are reported in Table 2. We found PON $\times$ time interactions $(P \leq 0.046)$ on total peripheral leukocyte counts (Figure 3a), neutrophil counts (Figure $3 \mathrm{~b}$ ), and the ratio of neutrophils to lymphocytes (data not shown, similar to neutrophil count presented in Figure 3b) during the BHV-1 challenge. Additionally, PON showed an effect $(P=0.013)$ on 
NUTRITION AND CALF RESPIRATORY INFLAMMATION RESPONSE

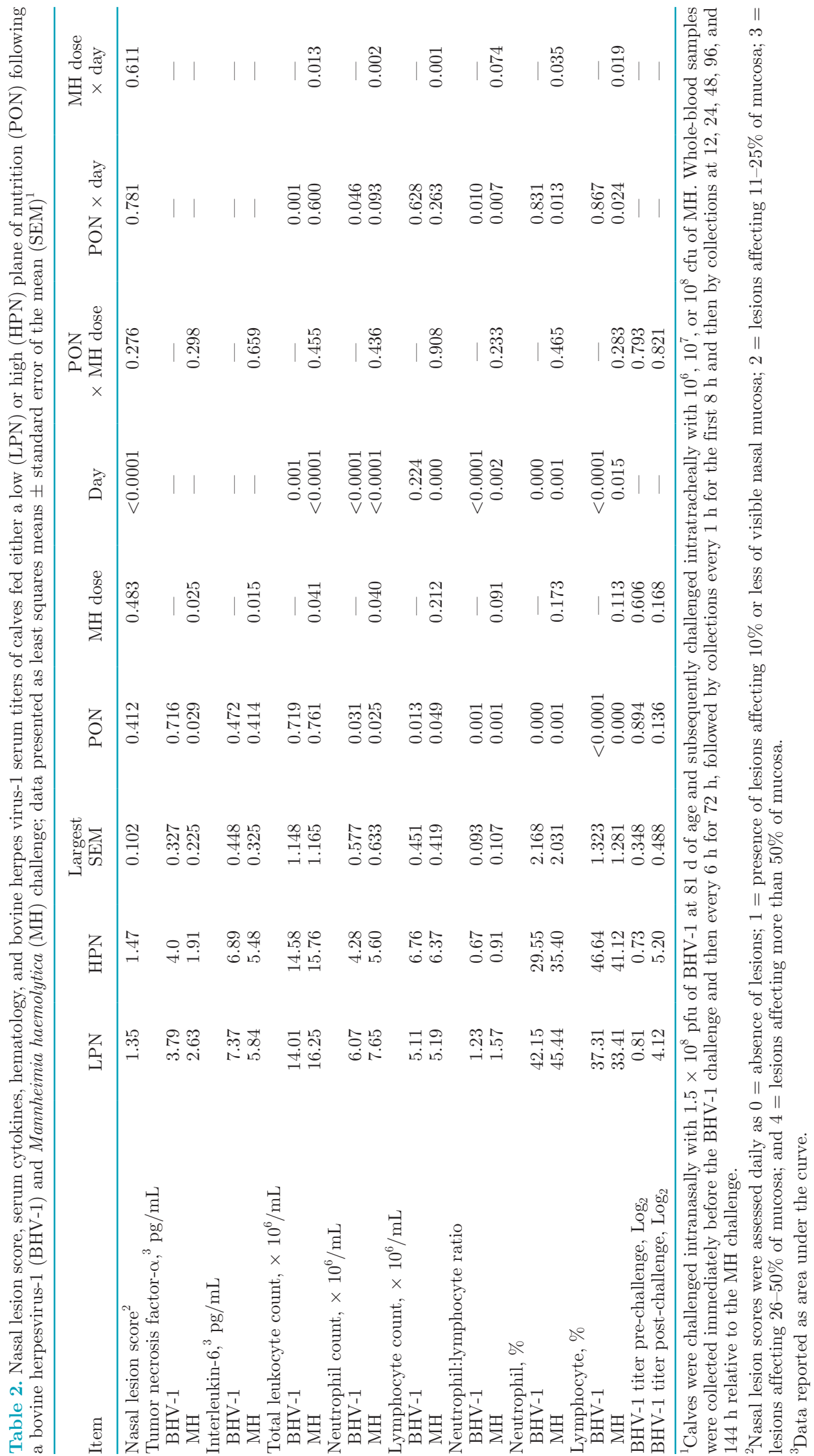


total peripheral blood lymphocyte counts during the BHV-1 challenge, in which HPN calves had higher lymphocyte counts compared with LPN calves. Following the $\mathrm{MH}$ challenge, $\mathrm{PON}$ displayed an effect $(P=0.025)$ on peripheral blood neutrophil counts, as LPN calves had higher neutrophil concentrations than HPN calves did. In contrast, analysis revealed a PON effect $(P=$ 0.049 ) on peripheral blood lymphocyte counts, as the HPN calves had higher lymphocyte concentrations than the LPN calves did. In addition, we found MH dose $\times$ time interactions $(P \leq 0.013)$ for total peripheral leukocyte counts (Figure 4a), neutrophil counts (Figure $4 \mathrm{~b}$ ), and lymphocyte counts (Figures 4c).

During the BHV-1 challenge, a PON effect $(P=$ 0.044) was observed in serum haptoglobin concentrations. Calves in the LPN treatment had higher $(P=$ $0.025)$ haptoglobin concentrations at $-24 \mathrm{~h}$ and tended $(P=0.055)$ to have higher concentrations at $0 \mathrm{~h}$ (Figure $5 \mathrm{a})$. Following the $\mathrm{MH}$ challenge, we found no PON $\times$ time or PON effects $(P \geq 0.293)$ on serum haptoglobin concentrations. However, we did discover an $\mathrm{MH}$ dose $\times$ time interaction $(P=0.007)$ on serum haptoglobin concentrations, wherein the $10^{7} \mathrm{MH}$ dose induced the highest $(P=0.043)$ haptoglobin concentrations at $24 \mathrm{~h}$, and the $10^{8} \mathrm{MH}$ dose induced the highest haptoglobin concentrations at $144 \mathrm{~h}(P<0.001$; Figure 5b).

Serum BHV-1 neutralizing antibody titer dilutions pre-challenge and $9 \mathrm{~d}$ following the BHV-1 challenge are reported in Table 2. No PON treatment differences $(P=0.894)$ were discovered in BHV-1 titers before the BHV-1 challenge. Further, we found no PON treatment differences $(P=0.136)$ in serum titers following the BHV-1 challenge.

\section{DISCUSSION}

Several studies have used either separate viral or bacterial models to study BRDC (Todd et al., 1972; McGuire and Babiuk, 1984; Gånheim et al., 2003), and others have used a combined viral-bacterial model similar to that used in the current study (Yates et al., 1983; Stabel et al., 1993; Hodgson et al., 2005). However, to our knowledge, no study has administered multiple doses of the bacterial pathogen to groups of animals

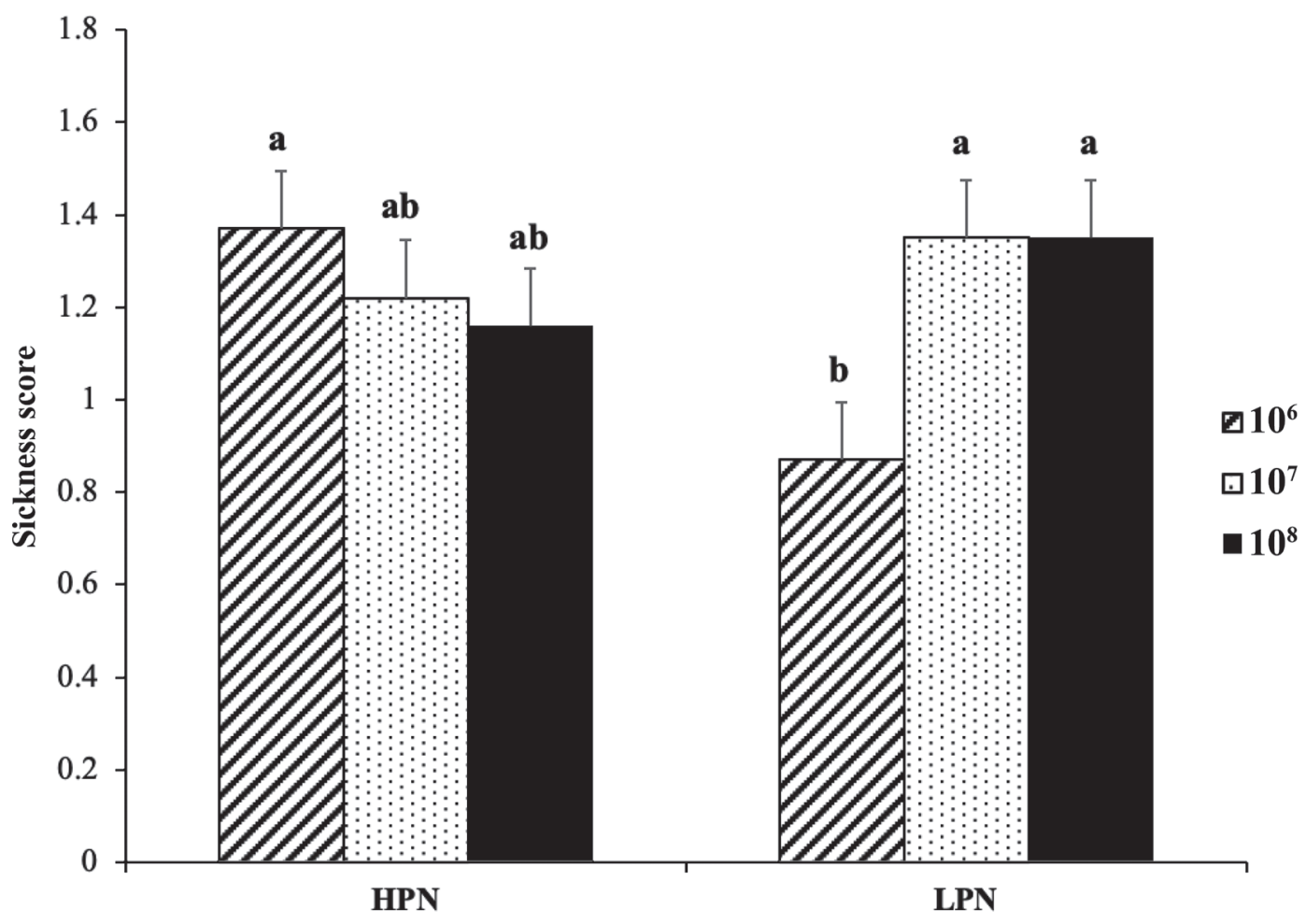

Pre-weaning plane of nutrition

Figure 1. Sickness scores $(0=$ alert, ears up; $1=$ depressed, head distended, ears droopy; $2=$ head extended; $3=$ lateral recumbency; $4=$ dead) among calves during a Mannheimia haemolytica (MH) challenge $72 \mathrm{~h}$ following a $1.5 \times 10^{8}$-pfu bovine herpesvirus-1 (BHV-1) challenge at $84 \mathrm{~d}$ of age. Calves were inoculated intratracheally with $10^{6}$ (diagonal striped bars), $10^{7}$ (dotted bars), or $10^{8}$ (solid black bars) cfu of MH. Calves were fed either a high (HPN) or a low (LPN) plane of nutrition (PON) with milk replacer until 54 d of age. Sickness scores were recorded every hour for the first $8 \mathrm{~h}$, followed by collections at $12,24,48,96$, and $144 \mathrm{~h}$ relative to the $\mathrm{MH}$ challenge. PON: $P=0.183 ; \mathrm{MH}$ dose: $P=0.019$; time: $P<0.001$; PON $\times$ MH dose: $P=0.003$; time $\times$ PON: $P=0.798$ : time $\times$ MH dose: $P=0.143$; time $\times$ PON $\times$ MH dose: $P=0.213$. Data are presented as least squares means \pm standard error of the mean. Least squares means estimates marked with different letters differ $(P \leq 0.05)$. 

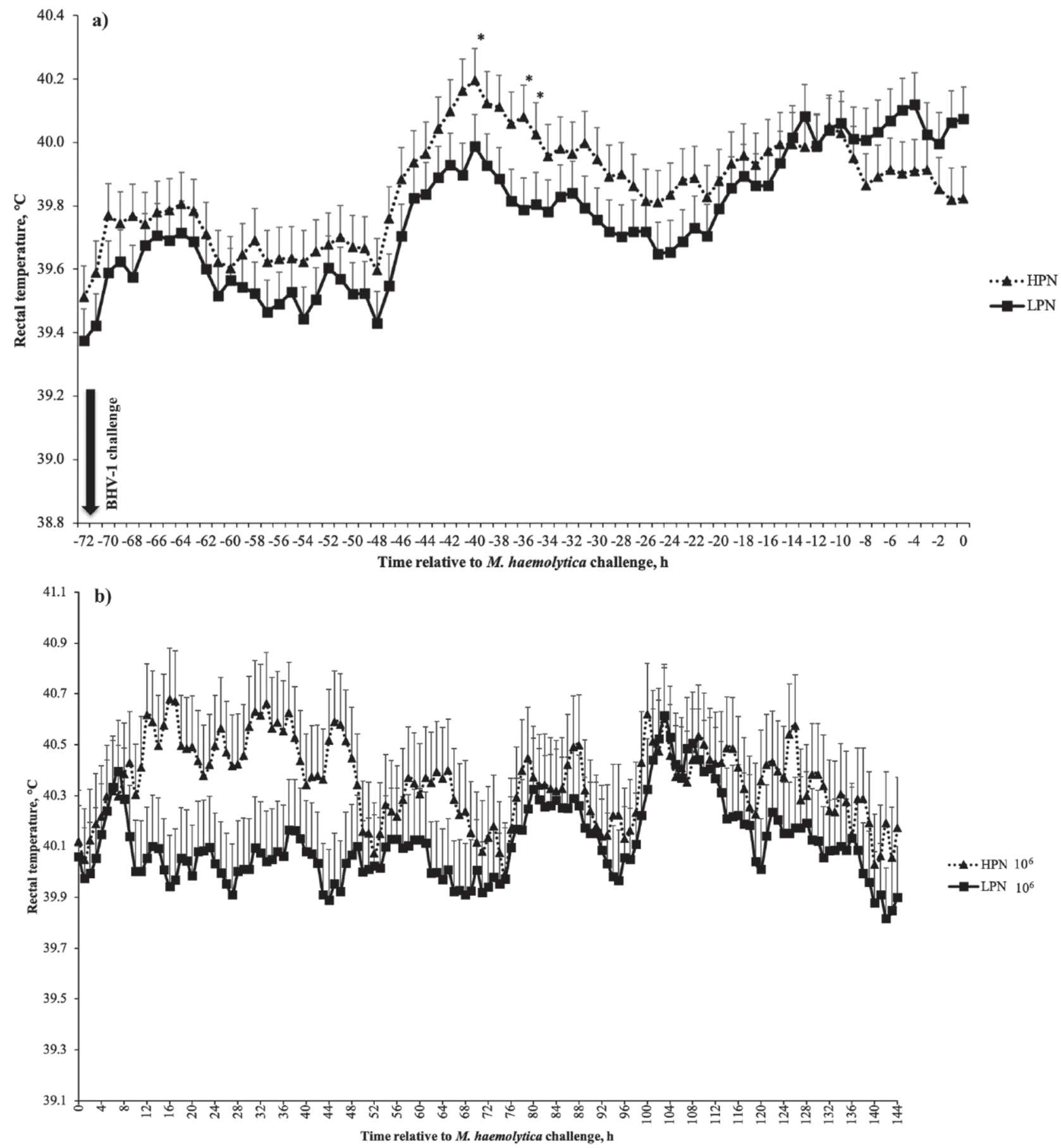

Figure 2. (a) Calf rectal temperature during a $1.5 \times 10^{8}$ pfu bovine herpesvirus-1 (BHV-1) challenge at $81 \mathrm{~d}$ of age, $72 \mathrm{~h}$ before a Mannheimia haemolytica $(\mathrm{MH})$ challenge. Calves were fed either a high (HPN; dotted line with triangles) or a low (LPN; solid line with squares) plane of nutrition (PON) with milk replacer until $54 \mathrm{~d}$ of age. Rectal temperature (RT) was recorded every 5 min beginning $72 \mathrm{~h}$ before the BHV-1 challenge $(0 \mathrm{~h})$ and averaged over 1 -h intervals. PON: $P=0.426$; time: $P<0.001 ; \mathrm{PON} \times$ time: $P<0.001$. The LPN calves tended $(P=0.071)$ to have a wider daily range of RT than did the HPN calves $\left(0.69\right.$ vs. $\left.0.58 \pm 0.042^{\circ} \mathrm{C}\right)$. ${ }^{*}$ indicates significant difference between treatments $(P \leq$ 0.05). All data are presented as least squares means \pm standard error of the mean. (b) Calf RT during $10^{6}$ cfu MH challenge (inoculated intratracheally) at $84 \mathrm{~d}$ of age, $72 \mathrm{~h}$ following BHV-1 challenge. Rectal temperature was recorded every 5 min beginning $72 \mathrm{~h}$ before the MH challenge at 0 h. PON: $P=0.293$; MH dose: $P=0.333$; time: $P<0.001$; PON $\times$ MH dose: $P=0.355$; time $\times$ PON: $P=0.868:$ time $\times$ MH dose: $P=$ 0.007; PON $\times$ MH dose $\times$ time: $P=0.001$. For all MH dosage levels, LPN calves tended $(P=0.087)$ to have a wider daily RT range than did HPN calves $\left(1.00\right.$ vs. $0.84 \pm 0.062^{\circ} \mathrm{C}$ ). (c) Calf RT during $10^{7}$ cfu $\mathrm{MH}$ challenge, $72 \mathrm{~h}$ following BHV-1 challenge. PON: $P=0.293 ; \mathrm{MH}$ dose: $P=0.333$; time: $P<0.001$; PON $\times$ MH dose: $P=0.355$; time $\times$ PON: $P=0.868$ : time $\times$ MH dose: $P=0.007 ; \mathrm{PON} \times \mathrm{MH}$ dose $\times$ time: $P$ $=0.001$. (d) Calf RT during a $10^{8}$ cfu $\mathrm{MH}$ challenge, 72 h following BHV-1 challenge. PON: $P=0.293 ;$ MH dose: $P=0.333 ;$ time: $P<0.001$; $\mathrm{PON} \times \mathrm{MH}$ dose: $P=0.355$; time $\times \mathrm{PON}: P=0.868$ : time $\times \mathrm{MH}$ dose: $P=0.007 ; \mathrm{PON} \times \mathrm{MH}$ dose $\times$ time: $P=0.001$ 

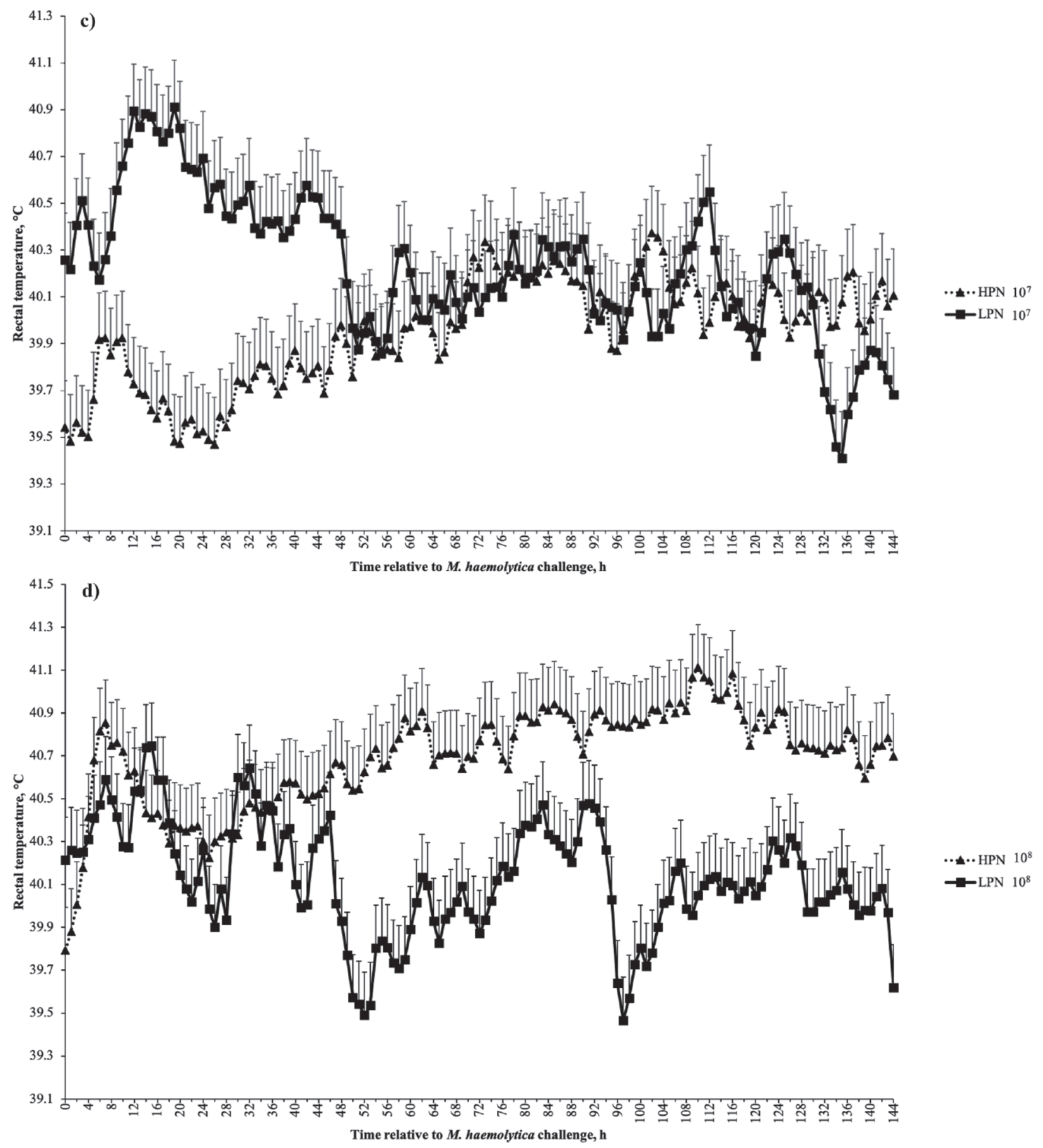

Figure 2 (Continued). (a) Calf rectal temperature during a $1.5 \times 10^{8}$ pfu bovine herpesvirus-1 (BHV-1) challenge at $81 \mathrm{~d}$ of age, $72 \mathrm{~h}$ before a Mannheimia haemolytica (MH) challenge. Calves were fed either a high (HPN; dotted line with triangles) or a low (LPN; solid line with squares) plane of nutrition (PON) with milk replacer until $54 \mathrm{~d}$ of age. Rectal temperature (RT) was recorded every 5 min beginning $72 \mathrm{~h}$ before the BHV-1 challenge $(0 \mathrm{~h})$ and averaged over 1 -h intervals. PON: $P=0.426$; time: $P<0.001$; PON $\times$ time: $P<0.001$. The LPN calves tended $(P=0.071)$ to have a wider daily range of RT than did the HPN calves $\left(0.69\right.$ vs. $\left.0.58 \pm 0.042^{\circ} \mathrm{C}\right) .{ }^{*}$ indicates significant difference between treatments $(P \leq 0.05)$. All data are presented as least squares means \pm standard error of the mean. (b) Calf RT during $10^{6}$ cfu MH challenge (inoculated intratracheally) at $84 \mathrm{~d}$ of age, $72 \mathrm{~h}$ following BHV-1 challenge. Rectal temperature was recorded every 5 min beginning $72 \mathrm{~h}$ before the $\mathrm{MH}$ challenge at 0 h. PON: $P=0.293$; $\mathrm{MH}$ dose: $P=0.333$; time: $P<0.001$; PON $\times \mathrm{MH}$ dose: $P=0.355$; time $\times$ PON: $P=0.868$ : time $\times \mathrm{MH}$ dose: $P=0.007 ; \mathrm{PON} \times \mathrm{MH}$ dose $\times$ time: $P=0.001$. For all $\mathrm{MH}$ dosage levels, LPN calves tended $(P=0.087)$ to have a wider daily $\mathrm{RT}$ range than did HPN calves $\left(1.00\right.$ vs. $\left.0.84 \pm 0.062^{\circ} \mathrm{C}\right)$. (c) Calf RT during $10^{7}$ cfu $\mathrm{MH}$ challenge, $72 \mathrm{~h}$ following $\mathrm{BHV}-1$ challenge. $\mathrm{PON}$ : $P=$ 0.293; $\mathrm{MH}$ dose: $P=0.333$; time: $P<0.001 ; \mathrm{PON} \times \mathrm{MH}$ dose: $P=0.355$; time $\times \mathrm{PON}: P=0.868:$ time $\times \mathrm{MH}$ dose: $P=0.007 ; \mathrm{PON} \times \mathrm{MH}$ dose $\times$ time: $P=0.001$. (d) Calf RT during a $10^{8}$ cfu $\mathrm{MH}$ challenge, $72 \mathrm{~h}$ following BHV-1 challenge. PON: $P=0.293 ; \mathrm{MH}$ dose: $P=0.333$; time: $P<0.001 ; \mathrm{PON} \times \mathrm{MH}$ dose: $P=0.355$; time $\times$ PON: $P=0.868$ : time $\times \mathrm{MH}$ dose: $P=0.007 ; \mathrm{PON} \times \mathrm{MH}$ dose $\times$ time: $P=0.001$. 
in the same experiment. Acute bronchopneumonia in cattle has been reported with isolated $\mathrm{MH}$ pathogen loads ranging from $2 \times 10^{3}$ to $1 \times 10^{9} \mathrm{cfu}$, with mortality observed in some animals with lung pathogen loads of $1 \times 10^{9} \mathrm{cfu}$ (McVey, 2007; Roof, 2011). These pathogen loads are consistent with the concentrations of $\mathrm{MH}$ administered in this study.

Many calves in the present study displayed biological indicators of morbidity, as demonstrated by altered RT, leukocyte counts, serum haptoglobin, and inflammatory
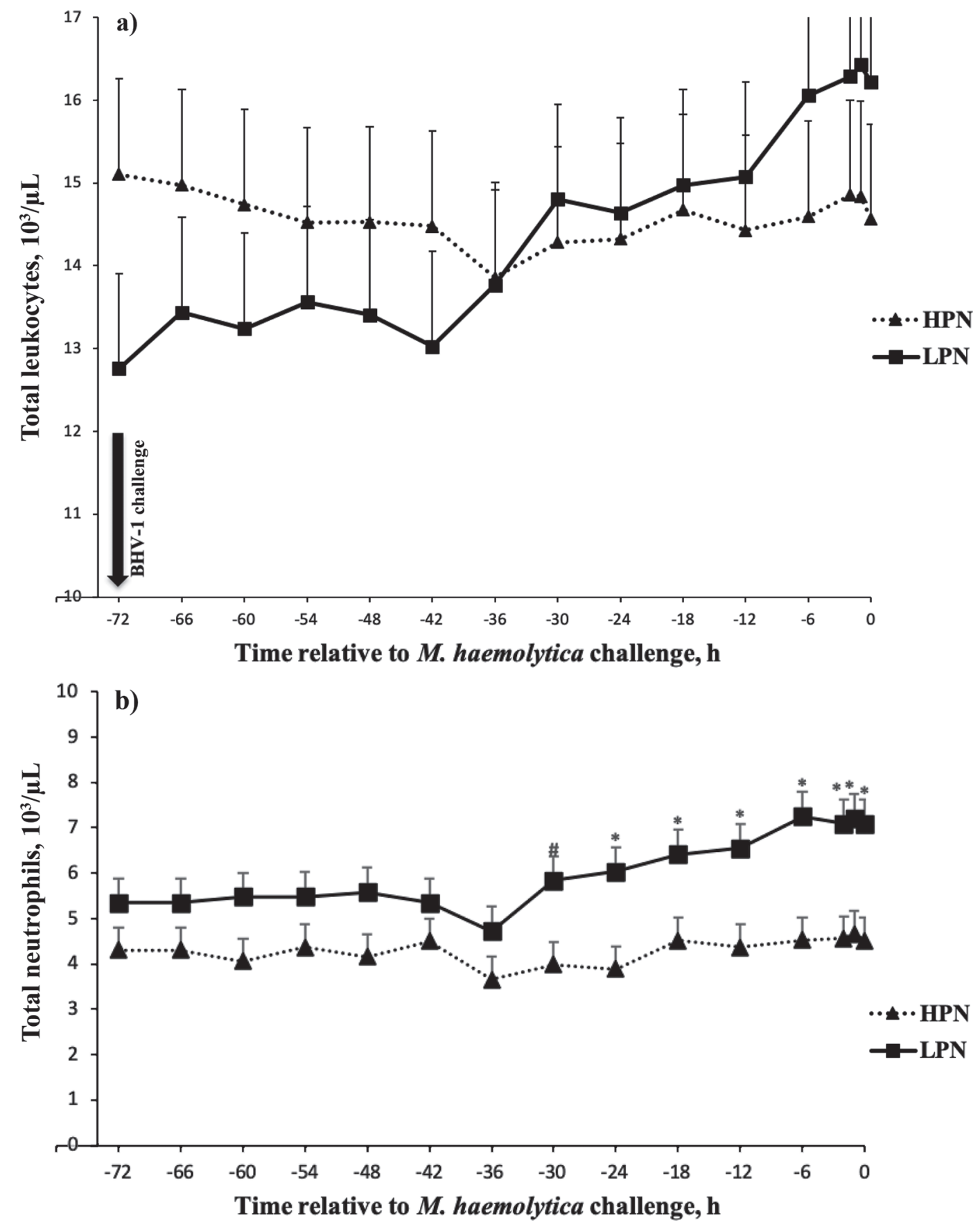

Figure 3. (a) Total leukocyte counts in calves intranasally inoculated with $1.5 \times 10^{8}$ pfu of bovine herpesvirus-1 (BHV-1) at $81 \mathrm{~d}$ of age, $72 \mathrm{~h}$ before a Mannheimia haemolytica challenge. Calves were fed either a high (HPN; dotted line with triangles) or a low (LPN; solid line with squares) plane of nutrition (PON) with milk replacer until $54 \mathrm{~d}$ of age. Blood samples were collected immediately before BHV-1 challenge, followed by every $6 \mathrm{~h}$ during the challenge for $72 \mathrm{~h}$. PON: $P=0.719$; time: $P=0.001$; time $\times \mathrm{PON}: P=0.001$. All data are presented as least squares means \pm standard error of the mean. (b) Total neutrophil counts in calves during BHV-1 challenge. PON: $P=0.031 ;$ time: $P<0.001$; time $\times$ PON: $P=0.046$. * indicates significant difference between treatments $(P \leq 0.05)$, and \# indicates a tendency between treatments $(0.10$ $<P<0.05)$. 

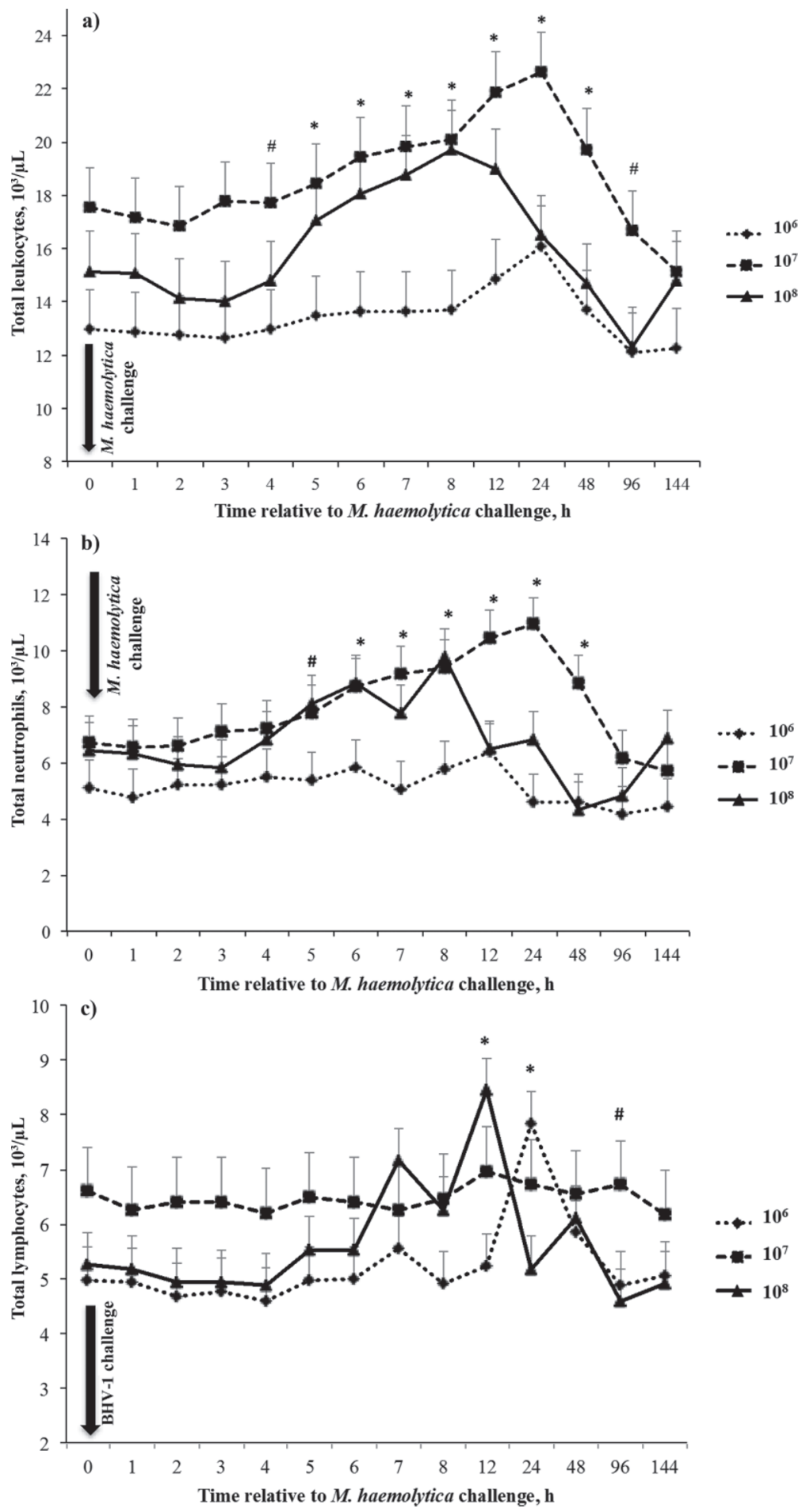

Figure 4. (a) Total leukocyte counts in calves during a Mannheimia haemolytica $(\mathrm{MH})$ challenge at $84 \mathrm{~d}$ of age, $72 \mathrm{~h}$ following a $1.5 \times 10^{8}$ pfu bovine herpesvirus-1 (BHV-1) challenge. Calves were inoculated intratracheally with $10^{6}$ (dotted line with diamonds), $10^{7}$ (dashed line with squares), or $10^{8}$ (solid line with triangles) cfu of MH. Calves were fed either a high (HPN) or a low (LPN) plane of nutrition (PON) with milk replacer until $54 \mathrm{~d}$ of age. Blood samples were collected every $2 \mathrm{~h}$ for the first $8 \mathrm{~h}$, followed by collections at 12, 24, 48, 96, and 144 h relative to MH challenge. PON: $P<0.761$; MH dose: $P=0.041$; time: $P<0.001 ; \mathrm{PON} \times \mathrm{MH}$ dose: $P=0.455 ;$ time $\times$ PON: $P=0.600$ : time $\times$ MH dose: $P=0.013$; time $\times \mathrm{PON} \times \mathrm{MH}: P=0.674$. All data are presented as least squares means \pm standard error of the mean. $*$ indicates significant difference between treatments $(P \leq 0.05)$, and \# indicates a tendency between treatments $(0.10<P<0.05)$. (b) Total neutrophil counts in calves during $\mathrm{MH}$ challenge. PON: $P=0.025$; $\mathrm{MH}$ dose: $P=0.040$; time: $P<0.001 ; \mathrm{PON} \times \mathrm{MH}$ dose: $P=0.436$; time $\times$ PON: $P=0.093$; time $\times$ MH dose: $P=0.002$; time $\times$ PON $\times$ MH: $P=0.893$. (c) Total lymphocyte counts in calves during MH challenge. PON: $P=0.049$; MH dose: $P=0.212$; time: $P<0.001$; PON $\times$ MH dose: $P=0.908$; time $\times$ PON: $P=0.263$ : time $\times$ MH dose: $P<0.001 ;$ time $\times$ PON $\times$ MH: $P=0.844$. 

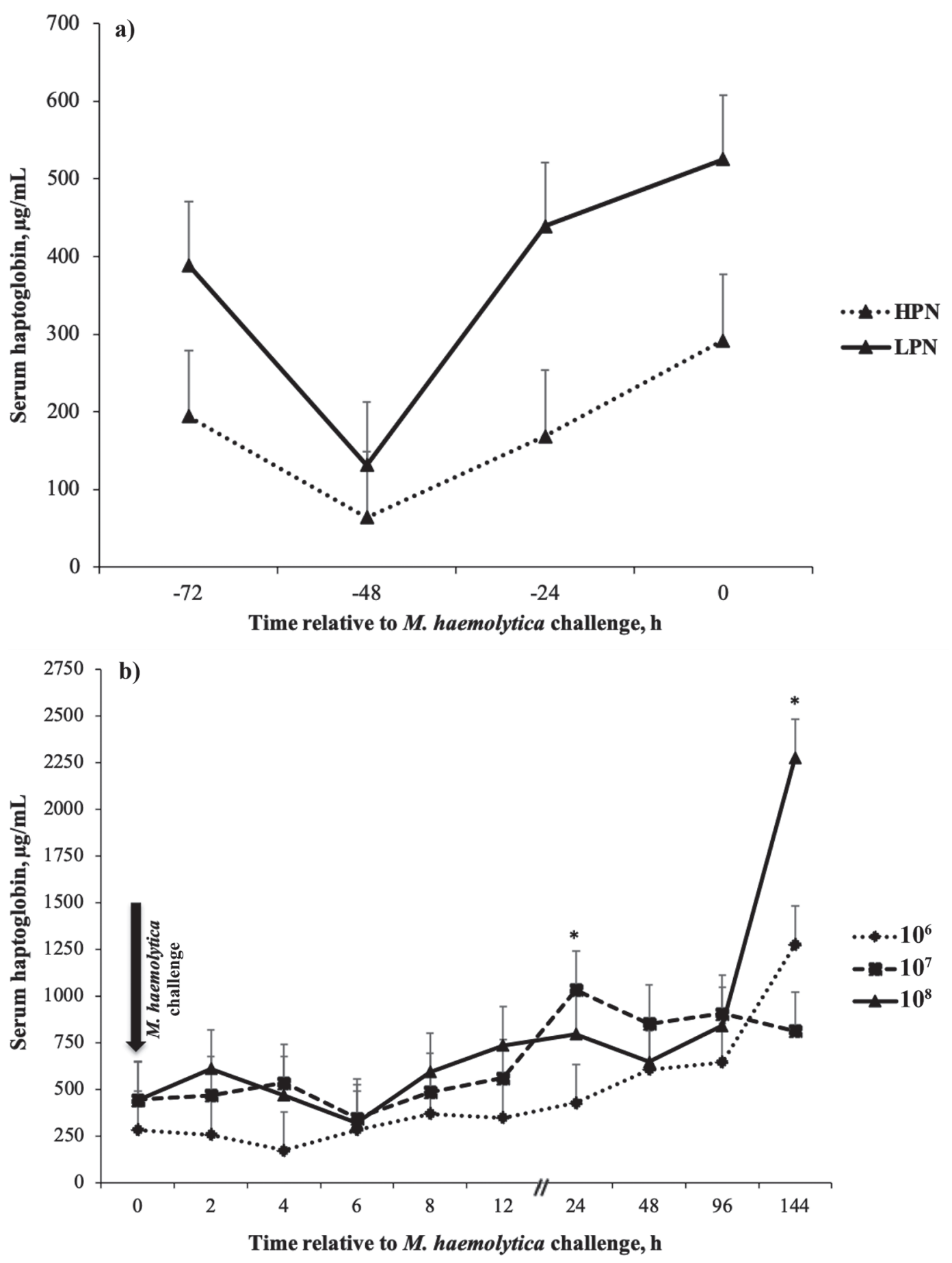

Figure 5. (a) Serum haptoglobin concentrations in calves intranasally inoculated with $1.5 \times 10^{8}$ pfu of bovine herpesvirus-1 (BHV-1) at 81 $\mathrm{d}$ of age, $72 \mathrm{~h}$ before a Mannheimia haemolytica $(\mathrm{MH})$ challenge. Calves were fed either a high (HPN; dotted line with triangles) or a low (LPN; solid line with squares) plane of nutrition (PON) with milk replacer until $54 \mathrm{~d}$ of age. Blood samples were collected immediately before the challenge, followed by every $24 \mathrm{~h}$ during the challenge for $72 \mathrm{~h}$. PON: $P=0.044$; time: $P=0.001$; time $\times$ PON: $P=0.595$. All data are presented as least squares means \pm standard error of the mean. ${ }^{*}$ indicates significant difference between treatments $(P \leq 0.05)$. (b) Serum haptoglobin concentrations in calves during $\mathrm{MH}$ challenge at $84 \mathrm{~d}$ of age, $72 \mathrm{~h}$ following BHV-1 challenge. Calves were inoculated intratracheally with $10^{6}$ (dotted line with diamonds), $10^{7}$ (dashed line with squares), or $10^{8}$ (solid line with triangles) cfu of MH. Blood samples were collected every 2 $\mathrm{h}$ for the first $8 \mathrm{~h}$, followed by collections at $12,24,48,96$, and $144 \mathrm{~h}$ relative to $\mathrm{MH}$ challenge. PON: $P=0.293 ; \mathrm{MH}$ dose: $P=0.333$; time: $P$ $<0.001 ; \mathrm{PON} \times \mathrm{MH}: P=0.355$; time $\times$ PON: $P=0.868$; time $\times \mathrm{MH}$ dose: $P=0.007$; time $\times$ PON $\times$ MH dose: $P=0.846$. Calves receiving the $10^{7} \mathrm{MH}$ dose showed the highest haptoglobin concentrations at $24 \mathrm{~h}$, but the $10^{8} \mathrm{MH}$ dose caused the highest haptoglobin concentrations at $144 \mathrm{~h}(P \leq 0.005)$. 
cytokine concentrations following both the BHV-1 and the $\mathrm{MH}$ challenges. Further, many calves showed clinical signs of disease following the $\mathrm{MH}$ challenge. Calves receiving the $10^{7}$ and $10^{8}$ dose of $\mathrm{MH}$ showed the greatest immunological activation. Total leukocytes, neutrophils, lymphocytes, and neutrophil-to-lymphocyte ratios were greater in calves administered the $10^{7}$ and $10^{8}$ doses compared with the $10^{6}$ dose. An acute inflammatory response was observed in calves that received the $10^{8}$ dose, as the neutrophil-to-lymphocyte ratio increased more rapidly and was greatest $5 \mathrm{~h}$ after the $\mathrm{MH}$ challenge in this group, compared with the $10^{6}$ and $10^{7}$ doses. The acute inflammatory response likely induced a rapid anti-inflammatory response in calves given the $10^{8}$ dose, which was apparent in the quick decrease in total leukocyte counts and neutrophil-to-lymphocyte ratios in peripheral circulation. Haptoglobin is a common acute-phase protein that changes concentration more slowly than pro-inflammatory cytokines such as TNF- $\alpha$ or IL-6, making it a more consistent measure of inflammation in the body over time. Cytokines such as TNF- $\alpha$ and IL-6 are common pro-inflammatory cytokines whose concentrations change very quickly, making them difficult diagnostic tools but good indicators of the acute response to disease. Serum concentrations of haptoglobin tended to be greater among calves challenged with the $10^{7}$ dose at 24 -h after the $\mathrm{MH}$ challenge compared with the $10^{6}$ and $10^{8}$ doses. In agreement, Ballou et al. (2011) reported that neonatal calves intravenously challenged with $1.5 \times 10^{7} \mathrm{cfu}$ of an enteropathogenic E. coli had greater plasma haptoglobin concentrations at 24 and $48 \mathrm{~h}$ post-challenge than did calves administered higher doses of the bacteria, either $1.5 \times 10^{8}$ or $1.5 \times 10^{9} \mathrm{cfu}$. However, in the present study the systemic inflammation seemed to persist in calves receiving the $10^{8} \mathrm{MH}$ dose, with haptoglobin concentrations nearly double those of the other treatments at 144 h. Gånheim et al. (2003) challenged calves with bovine viral diarrhea virus (BVDV) followed by a double inoculation of $\mathrm{MH} 5 \mathrm{~d}$ later, with an initial dose of $5 \times 10^{8}$ cfu and a second dose $2 \mathrm{~h}$ later of $7.5 \times$ $10^{9} \mathrm{cfu}$. Similarly, haptoglobin concentrations remained elevated in animals in this study for $12 \mathrm{~d}$ after $\mathrm{MH}$ challenge. These data suggest that the $10^{8}$ dose induced an acute disease response, and the $10^{6}$ and $10^{7}$ doses caused moderate inflammation and disease.

Early life nutrition may influence biological outcomes, including disease resistance later in life (Reik et al., 2001). In fact, Ballou (2012) and Ballou et al. (2015) reported that Jersey calves previously fed higher planes of MR nutrition showed improved ex vivo leukocyte responses and disease resistance, respectively, following an oral Salmonella enterica challenge approximately 1 mo after weaning. Data from the current study further support that previous plane of MR nutrition influences the pathophysiological response of calves to an experimental BHV-1 and $\mathrm{MH}$ BRDC challenge during the growing phase of life. Holstein calves previously fed the LPN diet had more severe pathophysiological responses following both BHV-1 and $\mathrm{MH}$ challenges. Following the BHV-1 challenge, LPN calves had greater measures indicative of systemic inflammation, such as increases in RT, higher peripheral blood total leukocyte and neutrophil counts, and higher serum haptoglobin concentrations. Likewise, after the MH challenge, LPN calves had higher neutrophil counts, higher neutrophil-tolymphocyte ratios, and higher levels of serum TNF- $\alpha$. Further, although the study was not designed to determine differences in mortality, 4 of 15 LPN calves either died or had to be euthanized soon after the observation period ended, whereas none of the HPN calves died or were euthanized.

Despite these calves being vaccinated twice during the pre-weaning period with an intramuscular modified-live vaccine that included $\mathrm{BHV}-1,70 \%$ of the calves were seronegative for BHV-1 immediately before the BHV-1 challenge. The low proportion of calves with seroconversion was likely attributable to the reduced number of mature B-cell populations in young calves (Kampen et al., 2006). Although we found no differences in serumneutralizing antibody titer concentrations in peripheral circulation, other factors due to vaccination may have resulted in greater protection against the BHV-1 challenge among HPN calves. Nasal mucosal protection with BHV-1-specific IgA was not determined in the current study, and this location and class of immunoglobulin is more important in the resistance to BHV-1 infection at the mucosa than it would be in the case of a systemic infection or other non-mucosal infections, as this is where the virus infected these calves (Mestecky et al., 1999). Further, aside from immunoglobulins, activation and induction of immunological memory in T-lymphocyte populations could improve protection from the BHV-1 challenge (Sun et al., 2009). In fact, HPN calves had higher lymphocyte concentrations in peripheral circulation than did LPN calves before the challenge, and developed higher BHV-1 serum-neutralizing antibody titer concentrations after the challenge with the live virus.

Decreases in thymic hormone and atrophy of the thymus gland have been induced in rodents by malnutrition, which impaired cell-mediated immunity (Chandra, 1992). Supporting a potential for impaired thymus gland development and cell-mediated immunity in calves previously fed an LPN, Foote et al. (2005b) reported that calves fed an HPN during the pre-weaning period had larger thymus glands (338 vs. $178 \mathrm{~g})$ at 6 wk of age compared with LPN-fed calves. Foote et 
al. (2005a) also reported that calves fed an HPN had fewer $\gamma \delta \mathrm{T}$ lymphocytes present at 8 wk of age. These $\mathrm{T}$ lymphocytes are more predominant in young animals, and a reduction in $\gamma \delta \mathrm{T}$ lymphocytes may indicate a more mature adaptive immune system. Additionally, an insufficient number of mature $\mathrm{T}$ lymphocytes would reasonably result in decreases of T-lymphocyte functionality as well as of immune processes that require $\mathrm{T}$ lymphocyte involvement. Griebel et al. (1987) reported that calves receiving $50 \%$ of maintenance energy requirements showed reduced antibody production following vaccination. Further supporting this notion, Walford et al. (1973) restrict-fed weanling mice $60 \%$ of a normal ad libitum diet, which resulted in a reduced number of antibody-forming cells and mitogenic responses that persisted for as long as $2 \mathrm{yr}$. Therefore, it is conceivable that feeding calves an LPN during the pre-weaning period can impair or delay the development of adaptive immune responses, which could increase the risk and persistence of infectious diseases.

A more severe infection due to BHV-1 could lead to altered susceptibility to a secondary bacterial challenge. Further, the different $\mathrm{MH}$ inoculum doses may require different pathophysiological responses for an optimal response to that infection challenge. For example, at lower infection doses, more robust innate immune responses may be effective at eliminating the bacteria before it is able to cause disease - or, at least, may limit the clinical course of the disease. Conversely, at higher infection doses, an overly aggressive innate response may cause excessive inflammation and tissue damage that is more detrimental to the animal than the infectious microorganism itself is. In fact, for RT and sickness scores after the $\mathrm{MH}$ challenge we found PON $\times \mathrm{MH} \times$ time and $\mathrm{PON} \times \mathrm{MH}$ interactions, respectively. The HPN calves had higher acute RT and sickness scores when challenged with the $10^{6}$ dose, which indicates that these calves' innate immune responses were acutely activated in response to the $\mathrm{MH}$ challenge. In contrast, the HPN calves had less dramatic acute RT responses when challenged with either the $10^{7}$ or $10^{8}$ doses, compared with the LPN calves. Although fever is generally beneficial, excessive fever or dysregulation of the febrile response may be a result of sepsis, which increases the risk of excessive local and disseminated tissue damage and consequently mortality (Clemmer et al., 1992). Many of the calves in the LPN treatment receiving the $10^{8}$ dose exhibited acute clinical signs indicative of sepsis, such as shivering, hyperventilation, and lateral recumbency. In fact, LPN calves had the lowest average RT, due to 3 of the 5 LPN calves having decreased RT over the first $72 \mathrm{~h}$ after the $\mathrm{MH}$ challenge, whereas the other 2 calves were elevated. The increased neutrophil counts in peripheral circulation at the time of the MH challenge among LPN calves may have primed them for the initial innate response to the $\mathrm{MH}$ at the $10^{6}$ dose; however, at higher concentrations of inoculum, the innate response may have been more aggressive and caused excessive inflammation, resulting in more pathology.

\section{CONCLUSIONS}

The results of this study demonstrate that a restricted plane of milk replacer during the pre-weaning period, as well as the level of $\mathrm{MH}$ dose used in a combined BHV-1 and MH challenge, influenced the inflammatory response. The lower doses of $\mathrm{MH}$ used in this study, $10^{6}$ and $10^{7} \mathrm{cfu}$, caused moderate inflammation and disease. In contrast, the highest dose, $10^{8} \mathrm{cfu}$, induced an acute disease response. Regardless, Holstein calves previously fed a restricted plane of milk replacer exhibited more severe pathophysiological responses to BRDC challenges, which likely increases the risk for morbidity and mortality associated with BRDC. The exact mechanisms underlying the increased risk among the previously restricted-fed calves is not completely clear, but these data suggest that development of the adaptive immune response may be impaired or delayed. Further, these data indicate an interaction between previous PON and the dose of $\mathrm{MH}$. A more robust inflammatory response observed among HPN at the low $\mathrm{MH}$ dose could be beneficial in pathogen elimination without excessive pathology. However, more severe inflammatory responses among LPN at higher MH doses could increase pathology and risk for mortality. Future research should evaluate the effects of previous plane of milk replacer nutrition on the risk for spontaneous BRDC, as well as further explore the underlying immunological mechanisms that contribute to altered risks of morbidity and mortality.

\section{ACKNOWLEDGMENTS}

This study was partially funded by a grant from the Texas Animal Nutrition Council (Dallas, TX). Milk replacer was donated by Land O'Lakes Animal Milk Products Company, Shoreview, MN. The authors thank Jeff Dailey, Jessica Carroll, Ryan Buchanan, and Chunfa $\mathrm{Wu}$, of the USDA-ARS Livestock Issues Research Unit (Lubbock, TX) for their help collecting data. Mention of trade names or commercial products in this article is solely for the purpose of providing specific information and does not imply recommendation or endorsement by the US Department of Agriculture. The USDA is an equal-opportunity provider and employer. 


\section{REFERENCES}

Ballou, M. A. 2012. Immune responses of Holstein and Jersey calves during the preweaning and immediate postweaned periods when fed varying planes of milk replacer. J. Dairy Sci. 95:7319-7330.

Ballou, M. A., C. J. Cobb, L. E. Hulbert, and J. A. Carroll. 2011. Effects of intravenous Escherichia coli dose on the pathophysiological response of colostrum-fed Jersey calves. Vet. Immunol. Immunopathol. 141:76-83.

Ballou, M. A., D. L. Hanson, C. J. Cobb, B. S. Obeidat, M. D. Sellers, A. R. Pepper-Yowell, J. A. Carrol, T. J. Earleywine, and S. D. Lawhon. 2015. Plane of nutrition influences the performance and innate leukocyte responses, and resistance to an oral Salmonella enterica serotype Typhimurium challenge in Jersey calves. J. Dairy Sci. 98:1972-1982.

Chandra, R. K. 1992. Protein-energy malnutrition and immunological responses. J. Nutr. 122:597-600.

Clemmer, T. P., C. J. Fisher, R. C. Bone, G. J. Slotman, C. A. Metz, and F. O. Thomas. 1992. Hypothermia in the sepsis syndrome and clinical outcome: The Methylprednisolone Severe Sepsis Study Group. Crit. Care Med. 20:1395-1401.

Davis Rincker, L. E., M. J. VandeHaar, C. A. Wolf, J. S. Liesman, L. T. Chapin, and M. S. Weber Neilsen. 2011. Effect of intensified feeding of heifer calves on growth, pubertal age, calving age, milk yield, and economics. J. Dairy Sci. 94:3554-3567.

FASS (Federation of Animal Science Societies). 2010. Guide for the Care and Use of Agricultural Animals in Research and Teaching. 3rd ed. FASS, Champaign, IL.

Foote, M. R., B. J. Nonnecke, M. A. Fowler, B. L. Miller, D. C. Beitz, and W. R. Waters. 2005a. Effects of age and nutrition on expression of CD25, CD44, and L-selectin (CD62L) on T-cells from neonatal calves. J. Dairy Sci. 88:2718-2729.

Foote, M. R., B. J. Nonnecke, W. R. Waters, M. V. Palmer, D. C. Beitz, M. A. Fowler, B. L. Miller, T. E. Johnson, and H. B. Perry. 2005b. Effects of increased dietary protein and energy on composition and functional capacities of blood mononuclear cells from vaccinated, neonatal calves. Int. J. Vitam. Nutr. Res. 75:357-368.

Gånheim, C., C. Hulten, U. Carlsson, H. Kindahl, R. Niskan, and K. P. Waller. 2003. The acute phase response in calves experimentally infected with Bovine Viral Diarrhoea Virus and/or Mannheimia haemolytica. J. Vet. Med. B Infect. Dis. Vet. Public Health. 50:183-190.

Griebel, P. J., M. Schoonderwoerd, and L. A. Babiuk. 1987. Ontogeny of the immune response: Effect of protein energy malnutrition in neonatal calves. Can. J. Vet. Res. 51:428-435.

Hodgson, P. D., P. Aich, A. Manuja, K. Hokamp, F. M. Roche, F. S. L. Brinkman, A. Potter, L. A. Babiuk, and P. J. Griebel. 2005. Effect of stress on viral-bacterial synergy in bovine respiratory disease: novel mechanisms to regulate inflammation. Comp. Funct. Genomics 6:244-250.

Kampen, A. H., I. Olsen, T. Tollersrud, A. K. Storset, and A. Lund. 2006. Lymphocyte subpopulations and neutrophil function in calves during the first 6 months of life. Vet. Immunol. Immunopathol. 113:53-63.

Makimura, S., and N. Suzuki. 1982. Quantitative determination of bovine serum Haptoglobin and its elevation in some inflammatory diseases. Nihon Juigaku Zasshi 44:15-21.
McGuire, R. L., and L. A. Babiuk. 1984. Evidence for defective neutrophil function in lungs of calves exposed to infectious bovine rhinotracheitis virus. Vet. Immunol. Immunopathol. 5:259-271.

McVey, D. S. 2007. Polymicrobial etiology of bacterial pneumonia associated with the bovine respiratory disease complex. In: American Association of Bovine Practitioners. p. 272.

Mestecky, J., M. W. Russell, and C. O. Elson. 1999. Intestinal IgA: Novel views on its function in the defense of the largest mucosal surface. Gut 44:2-5.

NAHMS. 2007. Beef 2007-08: Part IV: Reference of Beef Cow-calf Management Practices in the United States, 2007-08. USDA: APHIS: VS:CEAH, National Animal Health Monitoring Systems, Fort Collins, CO.

NAHMS. 2011. Feedlot 2011: Part IV: Health and Health Management on U.S. Feedlots with a Capacity of 1,000 or More Head. USDA APHIS: VS:CEAH, National Animal Health Monitoring Systems, Fort Collins, CO.

NRC (National Research Council). 2001. Nutrient Requirements of Dairy Cattle. 7th rev. ed. Natl. Acad. Press, Washington, DC.

Pruessner, J. C.. C. Kirschbaum, G. Meinlschmid, and D. H. Hellhammer. 2003. Two formulas for computation of the area under the curve represent measures of total hormone concentration versus time-dependent change. Psychoneuroendocrinology 28:916-931.

Reik, W., W. Dean, and J. Walter. 2001. Epigenetic reprogramming in mammalian development. Science 293:1089-1093.

Reuter, R. R., J. A. Carroll, L. E. Hulbert, J. W. Dailey, and M. L. Gaylean. 2010. Technical note: Development of a self-contained, indwelling rectal temperature probe for cattle research. J. Anim. Sci. 88:3291-3295.

Roof, C. 2011. Qualification and quantification of bacterial pathogen load in acute bovine respiratory disease cases. MS thesis, Department of Clinical Sciences, Kansas State University, Manhattan. http://krex.k-state.edu/dspace/handle/2097/11988

Soberon, F., E. Raffrenato, R. W. Everett, and M. E. Van Amburgh. 2012. Preweaning milk replacer intake and effects on long-term productivity of dairy calves. J. Dairy Sci. 95:783-793.

Stabel, J. R., J. W. Spears, and T. T. J. Brown. 1993. Effect of copper deficiency on tissue, blood characteristics, and immune function of calves challenged with infectious bovine rhinotracheitis virus and Pasteurella hemolytica. J. Anim. Sci. 71:1247-1255.

Sun, Y., R. T. Bailer, S. S. Rao, J. R. Mascola, G. J. Nabel, R. A. Koup, and N. L. Letvin. 2009. Systemic and mucosal T-lymphocyte activation induced by recombinant adenovirus vaccines in Rhesus monkeys. J. Virol. 83:10596-10604.

Todd, J. D., F. J. Volenec, and I. M. Paton. 1972. Interferon in nasal secretions and sera of calves after intranasal administration of avirulent infectious bovine rhinotracheitis virus: Association of interferon in nasal secretions with early resistance to challenge with virulent virus. Infect. Immun. 5:699-706.

Walford, R. L., R. K. Liu, M. Gerbase-Delima, M. Mathies, and G. S. Smith. 1973. Longterm dietary restriction and immune function in mice: Response to sheep red blood cells and to mitogenic agents. Mech. Ageing Dev. 2:447-454.

Yates, W. D., L. A. Babiuk, and K. W. Jericho. 1983. Viral-bacterial pneumonia in calves: Duration of the interaction between bovine herpesvirus 1 and Pasteurella haemolytica. Can. J. Comp. Med. $47: 257-264$. 